\begin{tabular}{|c|c|c|}
\hline & $\begin{array}{l}\text { International Journal of Environment, Agriculture and Biotechnology } \\
\qquad \text { Vol-6, Issue-3; May-Jun, } 2021\end{array}$ & $Q=$ \\
\hline IJEAB & $\begin{array}{c}\text { Journal Home Page Available: } \underline{\text { https://ijeab.com/ }} \\
\text { Journal DOI: } 10.22161 / \text { ijeab }\end{array}$ & \\
\hline
\end{tabular}

\title{
Utilization of Signal Global Navigation Satellite System (GNSS) for Meteorological
}

\author{
Syachrul Arief
}

Geospatial Information Agency Indonesia

Email: syachrul.arief@big.go.id

Received: 09 Apr 2021; Received in revised form: 16 May 2021; Accepted: 03 Jun 2021; Available online: 17 Jun 2021

(C)2021 The Author(s). Published by Infogain Publication. This is an open access article under the CC BY license

(https://creativecommons.org/licenses/by/4.0/).

\begin{abstract}
In this study, I show that microwave signals emitted from satellites and received by the GNSS system can be utilized for meteorological purposes, such as heavy rain in Indonesia, using open-source software goGPS. Comparison of the gradient of the North and East atmospheric delays between goGPS, IGS, and UNR. The correlation of the results of goGPS with those from IGS and UNR is relatively high. The gradient of the late goGPS and IGS, and UNR products show good consistency. This means that the process of goGPS is good enough to get an accurate value. The standard deviation and RMS difference between goGPS and IGS are 16.99 and -1.32 (in $\mathrm{mm}$ ), respectively. The ones for the goGPS-UNR pair are 18.33 and -1.08. goGPS software works very well at different times and stations. This means that the goGPS software package can be an alternative to commercial software systems for ZTD estimation. The correlation of PWV values from GPS and radiosonde for the dry and rainy seasons are 0.84 and 0.73 , respectively. PWV values during this dry period show a downward trend and an upward trend during the wet season period.
\end{abstract}

Keywords—Tropospheric, PWV, Signal, GNSS.

\section{INTRODUCTION}

As is generally known, the primary function of GNSS is to determine the position, speed, and time information in almost all places on earth, at any time and in any weather conditions. GNSS satellites broadcast microwave signals to GNSS receivers near the earth's surface to obtain position information. Then from the microwave signal data, much information is obtained through the process and extraction stages following the needs and objectives of the study.

This study aims to show that microwave signals from GNSS satellites can be used for meteorological purposes. Examples of meteorological events in this study are the heavy rain conditions in several places in Indonesia.

From this microwave signal, I process and extract it to get tropospheric delay information. From this tropospheric data, I convert it into Precipitation water vapor (PWV). PWV represents the condensation conditions of water ISSN: 2456-1878

https://dx.doi.org/10.22161/ijeab.63.15 vapor in the column in a particular area. This study in Indonesia is the first report that the GNSS microwave signal process is used to obtain information related to heavy rain conditions by using open-source software. Therefore this study can be a value-added use of microwave signals from GNSS for meteorological events.

\section{DATA DAN METHOD}

\section{PWV Retrieved from GPS}

The GNSS data's primary format in this study is the Receiver Independent Exchange (RINEX) format. In the first station, I use the BAKO station managed by BIG / BAKOSURTANAL, and I use, as the second station, the JOG2 station, which is managed by GFZ (Geoforschungs Zentrum), the German Geo-research Center. As the period of this study, I use days of the year (DOY) 022-025, 2225 January, and DOY 230-233, August 17-20, 2018. The 
former represents the rainy season, and the latte represents the dry season. Next, I process RINEX files to estimate tropospheric parameters using goGPS, an advanced open-source GNSS software, version 1.0 Beta, from Geomatics Research and Development s.r.l. Lomazzo, Italy [Realini, 2009].

The leading software for processing RINEX data, goGPS. [Realini, 2009] is an open-source software initially developed by Dr. E. Realini in 2007 at the Geomatics Laboratory of the Politecnico di Milano, Como Campus. It is specifically designed to improve the low-cost positioning accuracy of GNSS devices by relative positioning and the Kalman filtering technique. The goGPS code was distributed online as free and opensource software in 2009. The project has been open to collaboration since publication. It has received supports and code contributions from users working in both academy and business companies in different countries (including Italy, Japan, Switzerland, Spain, and Germany). Strategies for processing RINEX data with goGPS are as shown below,

\section{Constellation: multi GNSS}

2. Processing Technique: Precision Point Positioning (PPP)

\section{Elevation cut-off angle: $7^{\circ}$}

4. Processing rate: once in 5 minutes

5. Mapping functions: the Niell mapping functions (NMF)

6. Ionosphere modeling: ionosphere-free linear combination

7. Dynamic model: static

8. Frequency: L1, L2

9. Types of observation data: code and phase

Accurate point positioning is used as a post-processing method for determining absolute position using standalone (thus un-differenced) GNSS receivers. GNSS PPP processing uses the ionosphere-free combinations of dualfrequency pseudoranges and carrier-phase observations. The preference for PPP instead of double-difference (DD) processing arises from the benefit that (1) each GNSS station can be processed independently and that (2) Continuous observation of the same satellite at two stations is not required (Yuan et al. 2014). To compare and validate the ZTD values, I estimated with goGPS. I used two international tropospheric products from International GNSS Services (IGS) with commercial software version 5 of the Bernese software. The other products from the University of Nevada Reno (UNR) were obtained using the GIPSY / OASIS II software from
NASA Jet Propulsion Laboratory (JPL) [Blewitt et al., 2018].

\section{RESULT AND DISCUSSION}

In this section, the process and extraction of the GNSS microwave signal in the discussion below I compare with other parameters and a validation test of the accuracy of both the opensource software and the value of the process result obtained.

\section{A. Comparison of the estimated tropospheric delay gradients with other products}

Here I compare estimated atmospheric delay gradient vectors using the data from the JOG2 station on August 20, 2018, with those from other products, namely those from IGS and UNR. The correlation of the goGPS and IGS delay gradient values for the north is 0.47 and 0.41 for the east, while the correlation between the goGPS and UNR delay gradient values is 0.71 for the north and 0.75 for the east. I plot them in Figure 1.

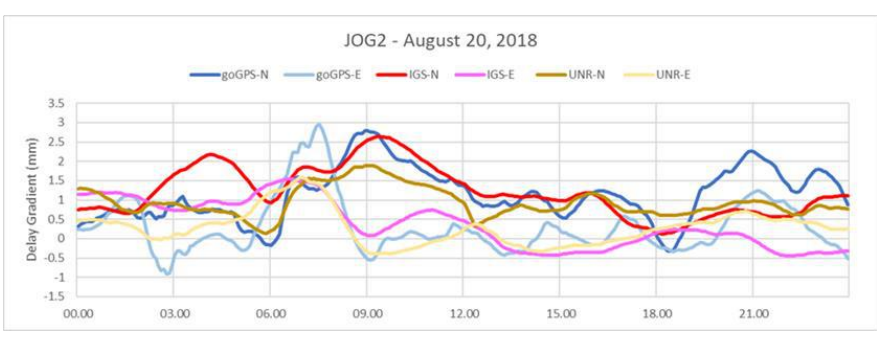

Fig.1: Comparison of North and East atmospheric delay gradient between goGPS, IGS, and UNR. The correlation of goGPS results with those from IGS and UNR is relatively high

The goGPS delay gradients, and the IGS and UNR products show good consistency. This means that the process on goGPS is good enough to get accurate values of not only the ZTD but also the delay gradients. Therefore, in this research, I estimate ZTD using goGPS software together with the tropospheric delay gradients

\section{B. ZTD range value from goGPS}

First, I process data from the BAKO and JOG2 stations from 22 to January 25, 2018. The rate of atmospheric parameter estimation is every 5 minutes, and so we get 288 values for one day ( 24 hours). From these 288 data, I get the smallest, the most significant, and the average values, as presented in Figure 2.

Next, I carried out the same process from 18 to August 21, 2018. The results in Figure 3. The ZTD value from 22 to January 25, 2018 (rainy season) at BAKO stations tends to be higher than 18 to August 21 (dry 
season) 2018. Likewise, at the JOG2 station, ZTD in January 2018 is higher than those in August.

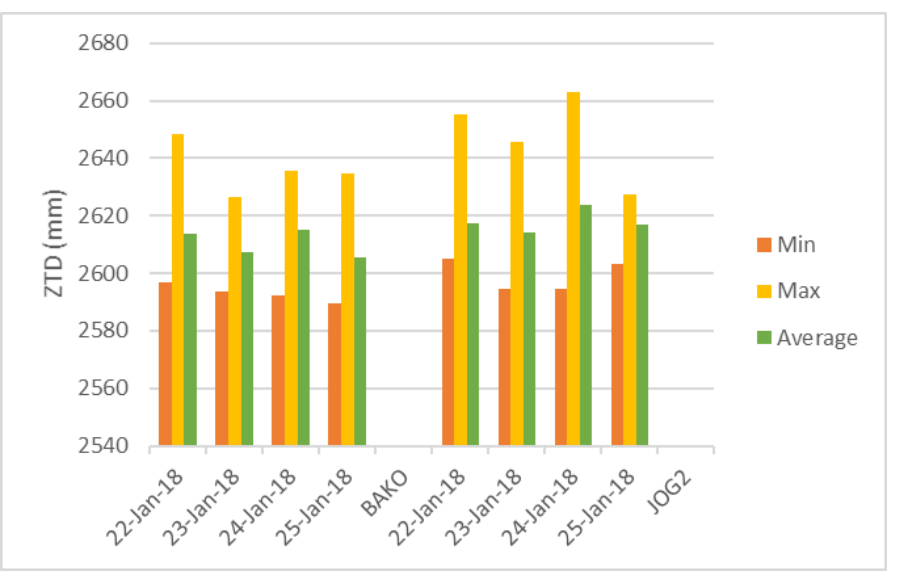

Fig.2: Minimum, maximum, and the average ZTD values for 22-25 Jan 2018 at BAKO and JOG2 stations

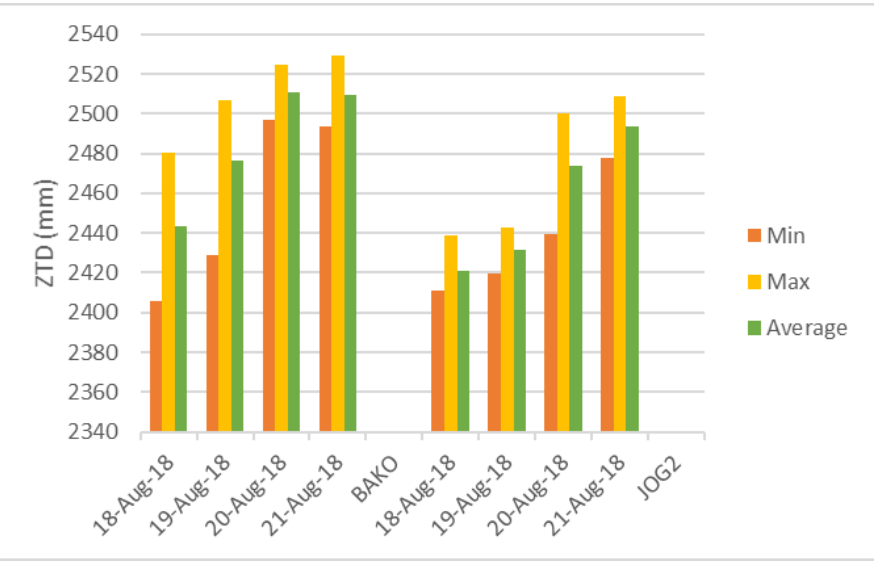

Fig.3: Minimum, maximum, and the average ZTD values for 18-21 Aug. 2018 at the BAKO and JOG2 stations. The difference of about $-100 \mathrm{~mm}$ from those shown in Figure 2 reflects the smaller amount of water vapor during the dry season.

\section{Comparison of the ZTD values of goGPS, IGS and UNRs}

Next, I compare the ZTD values for the three solutions, namely goGPS, IGS, and UNR, using the BAKO and JOG2 stations on January 24, 2018, and August 20, 2018. This is part of the validation process of determining ZTD values with goGPS.

The results obtained were small RMS values $<2 \mathrm{~mm}$. If the RMS is relatively tiny, the troposphere parameters estimated by goGPS show a good agreement with the products from UNR and IGS.

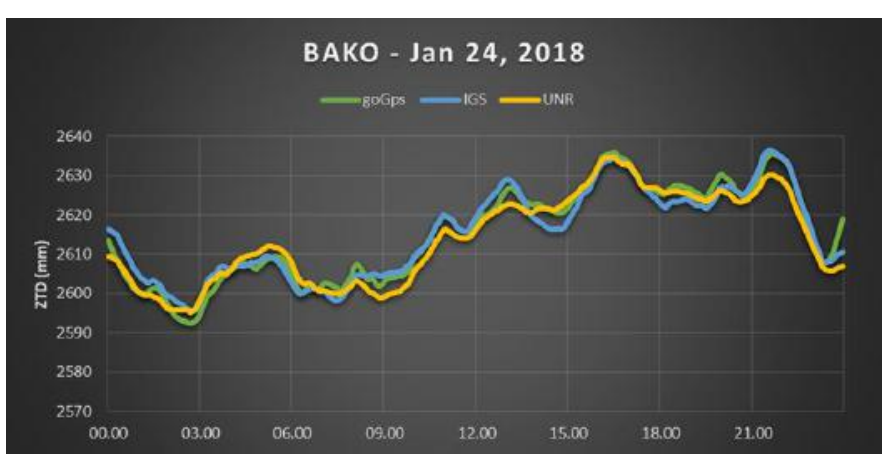

Fig.4: ZTD time series from goGPS, IGS, and UNR, on 24, Jan. 2018, at the BAKO station. The standard deviation and RMS of the difference between goGPS and IGS are 12.03, 0.81, respectively (in $\mathrm{mm}$ ). Those for the goGPS-UNR pair are 11.22, 0.66

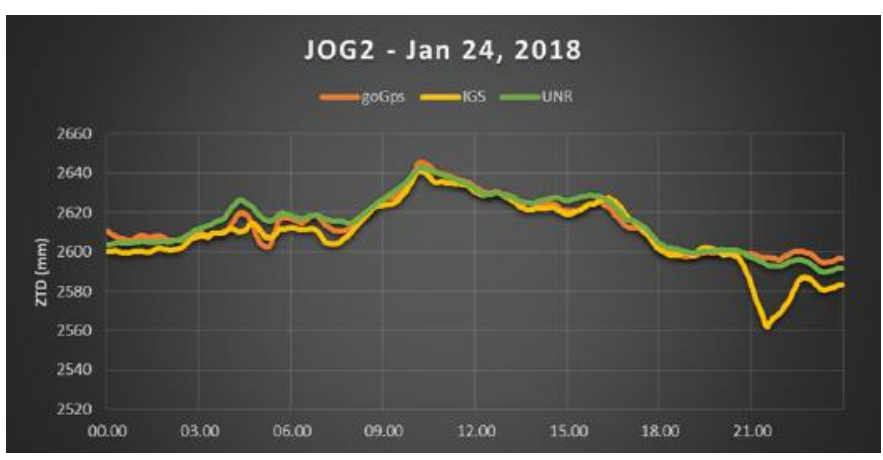

Fig.5: Same as in Figure 4, but the JOG2 station replaces the BAKO station. The standard deviation and RMS of the difference between goGPS and IGS are 16.11 and 1.11, respectively (in $\mathrm{mm}$ ). Those for the goGPS-UNR pair are $15.00,1.63$

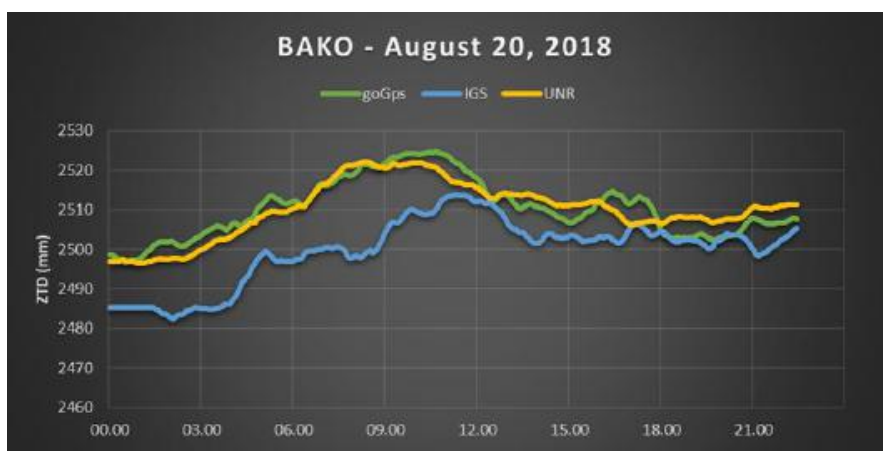

Fig.6: Same as Figure 4, but the date is August 20, 2018. The standard deviation and RMS of the difference between goGPS and IGS are 7.44 and -0.66 , respectively (in $\mathrm{mm}$ ).

Those for the goGPS-UNR pair are 8.09 and 0.26 


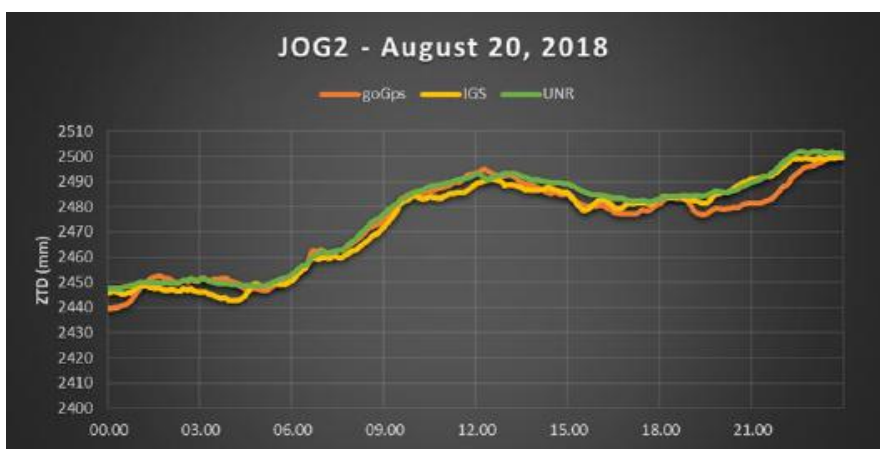

Fig.7: Same as in Figure 6, but the JOG2 station replaces the BAKO station. The standard deviation and RMS of the difference between goGPS and IGS are 16.99 and -1.32, respectively (in $\mathrm{mm}$ ). Those for the goGPS-UNR pair are 18.33 and -1.08

The results of the ZTD values that I obtained using goGPS, both on January 24 and August 20 and the BAKO and JOG2 stations, are shown in Figures 4 - 7. The whole pictures show the consistency of the ZTD value from goGPS with other solutions. The GoGPS software works very well at different times and stations. Then the goGPS software package can be an alternative to commercial software systems for ZTD estimation.

\section{Comparison of $P W V$ and rainfall}

The software package goGPS can estimate ZTD and convert the isolated ZWD to PWV values. Here I try to compare the PWV value of GPS at the CMAK station in Makassar, South Sulawesi, with the PWV value observed at the WAAA radiosonde station Makassar City. I perform the comparison in the dry season, April - September 2015, and in the rainy season, October 2015 - March 2016. The results are given in Figures 8 and 9.

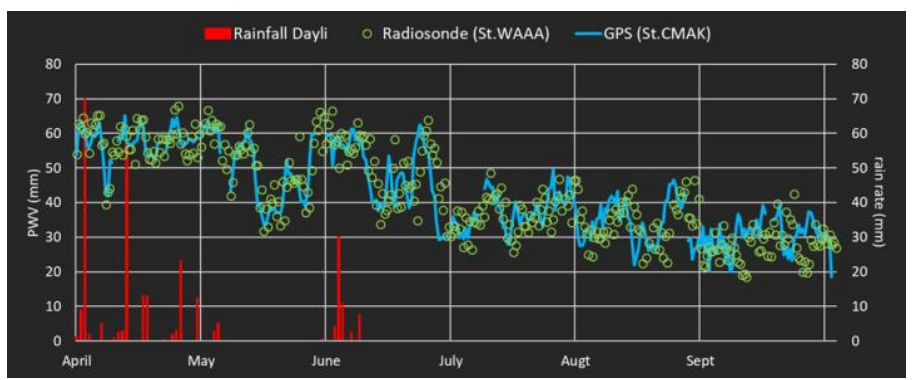

Fig.8: This is a comparative image of PWV from goGPS and $P W V$ radiosonde, and daily rainfall data in the city of Makassar during the dry season in 2015
The figures also show that the PWV value during this dry period has a downward trend (Figure 8) and an upward trend during this period of the rainy season (Figure 9). The PWV values from goGPS and radiosonde are primarily consistent with each other.

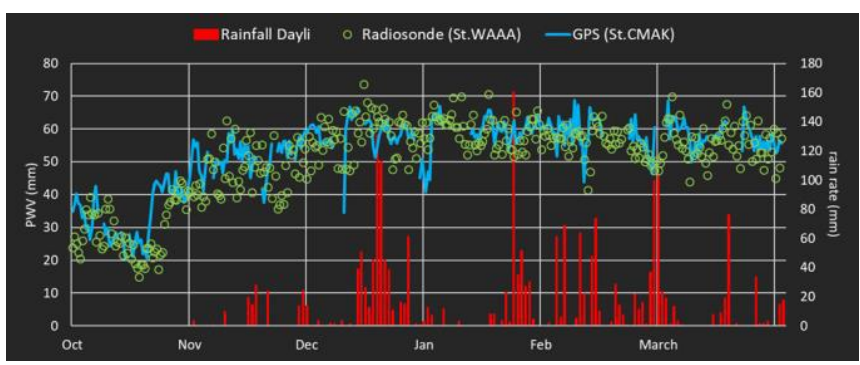

Fig.9: Comparison of PWV values estimated by the goGPS software and those measured by radiosonde, together with the daily rainfall data in Makassar. The period corresponds to the rainy season from 2015 to 2016

\section{CONCLUSION}

The correlation of the results of goGPS with those from IGS and UNR is relatively high. The gradient of the late goGPS and IGS, and UNR products show good consistency. This means that the process of goGPS is good enough to get an accurate value.

Figures 4 through 7 show the consistency of ZTD values from goGPS with IGS and UNR solutions. GoGPS software works very well at different times and stations. This means that the goGPS software package can be an alternative to commercial software systems for ZTD estimation.

Comparison of PWV values from goGPS and radiosonde, together with daily rainfall data in the city of Makassar during the dry season and rainy season in 2015-2016, shows the correlation of PWV values from GPS and radiosonde is quite good. PWV values of goGPS and radiosonde are primarily consistent with each other.

\section{ACKNOWLEDGMENT (Heading 5)}

The author would like to thank Geospatial Information Agency (BIG) Indonesia for providing GNSS data, Meteorology and Climatology Agency (BMKG) Indonesia for providing radiosonde data, Geomatics Laboratory of Politecnico in Milano, Como Campus for providing the open-source goGPS software, and IGS (USNO, CODE) and UNR for providing GNSS observations and final ZTD.

The correlation of PWV values from GPS and radiosonde for the dry season in Figure 8 and the rainy season in Figure 9 are 0.84 and 0.73 , respectively. 


\section{REFERENCES}

[1] Blewitt, G., W. C. Hammond, and C. Kreemer (2018), Harnessing the GPS data explosion for interdisciplinary science, Eos, 99, https://doi.org/10.1029/2018EO104623.

[2] Enge, P., \& Misra, P. (2006). Global Positioning System (2 ed.). Ganga-Jamuna Press.

[3] Gabor, M. (1997, May 5). Remote Sensing of Water Vapor from GPS Receivers. Retrieved May 16, 2018, from http://www.csr.utexas.edu/texas_pwv/midterm/gabor/gabor .html\#anchor561367.

[4] Iwabuchi, Tetsuya \& Miyazaki, Shin'ichi \& Heki, Kosuke \& Naito, Isao \& Hatanaka, Yuki. (2003). An impact of estimating tropospheric delay gradients on tropospheric delay estimations in the summer using the Japanese nationwide GPS array. Journal of Geophysical Research. 108. 10.1029/2002JD002214.

[5] Koning, A. (2016). Precipitable water vapor estimation using GPS in Uganda: A study on obtaining the Zenith Wet Delay. Delft, The Netherlands.

[6] K. Yedukondalu, A. S. (2011). Estimation and Mitigation of GPS Multipath Interference Using Adaptive Filtering. Progress in Electromagnetics Research M(21), 133-148.

[7] Nicholas Zinas. (2019, October 04). Satellite and receiver clock errors. Retrieved from Tekmon Geomatics: http://www.tekmon.eu/1-3-2-satellite-and-receiver-clockerrors.

[8] Realini E (2009) goGPS free and constrained relative kinematic positioning with low-cost receivers. Ph. D. thesis,

http://www.researchgate.net/publication/237520116X. S. $\mathrm{Li}$, et al., "Analysis and Simplification of ThreeDimensional Space Vector PWM for Three-Phase FourLeg Inverters," IEEE Transactions on Industrial Electronics, vol. 58, pp. 450-464, Feb 2011.

[9] Yuan, Yubin, Kefei Zhang, Witold Rohm, Suelynn Choy, Robert Norman, and Chuan-Sheng Wang. 2014. "RealTime Retrieval of Precipitable Water Vapor from GPS Precise Point Positioning." Journal of Geophysical Research: Atmospheres 119 (16): 10044-57. https://doi.org/10.1002/2014JD021486. 